\title{
Rehabilitation is an Important Pillar of the Treatment in Patients with Niemann Pick Disease Type C: A Case Report
}

\author{
Rehabilitasyon Niemann Pick Hastalığı Tip C Tanılı Hastalarda \\ Tedavinin Önemli Bir Ayağıdır: Olgu Sunumu
}

Dilek BADAY KESKiN, Tülay TIFTIK, Meltem DALYAN, Ayşe SEVIM KALIN

Ankara Physical Medicine and Rehabilitation Training and Research Hospital, Department of Physical Medicine and Rehabilitation Ankara, Turkey

\begin{abstract}
Niemann Pick disease type $\mathrm{C}$ is a rare, progressive lysosomal lipid storage disease and is inherited in an autosomal recessive manner. Clinical presentation of Niemann Pick disease type $\mathrm{C}$ is very heterogeneous. Early diagnosis and appropriate approach including symptomatic and disease-specific treatment can improve the patient's quality of life. Because of neurological manifestations of the disease, rehabilitation must be a part of the treatment for protecting patients from complications of illness and immobilization. To the best of our knowledge, the rehabilitation protocol for Niemann Pick disease type C has not been reported before. In this article, we presented an 8-year-old female patient who was diagnosed with Niemann Pick disease Type C five years ago and was not able to ambulate for the last one year. She received a comprehensive rehabilitation program for eight weeks in addition to miglustat treatment.
\end{abstract}

Key Words: Metabolic disease, Niemann Pick disease type C, Rehabilitation

öz

Niemann Pick hastalı̆ı Tip C nadir görülen, progresif, otozomal resesif bir lipid depo hastalığıdır. Niemann Pick hastalığı Tip C'nin klinik prezentasyonu oldukça farklılık göstermektedir. Erken tanı ve uygun yaklaşım (semptomatik ve hastalığa spesifik tedaviler) hastaların yaşam kalitesini artırmaktadır. Hastalığın nörolojik manifestasyonları nedeniyle, hastaları hastalık ve immobilizasyon komplikasyonlarından korumak için, rehabilitasyon tedavinin bir parçası olmalıdır. Bildiğimiz kadarılla daha önce Niemann Pick hastalı̆̆ı Tip C'nin rehabilitasyon protokolü bildirilmemiştir. Yazıda beş yll önce Niemann Pick hastalığı Tip C tanısı konan, bir yıldır ambule olamayan 8 yaşında kız hasta sunulmaktadır. Hastaya miglustat tedavisinin yanı sıra sekiz hafta süre ile kapsamlı rehabilitasyon programı uygulanmıştır.

Anahtar Sözcükler: Metabolik hastallk, Niemann Pick hastalı̆ı tip C, Rehabilitasyon

\section{INTRODUCTION}

Niemann Pick disease type C (NP-C) is a progressive and atypical lysosomal lipid storage disease due to the mutations in the NPC1 or the NPC2 gene, and it is inherited in an autosomal recessive manner (1-4). The incidence of NP-C is estimated as 1 per 120.000 live births $(1,2,5)$. Since NP-C has a heterogeneous clinical presentation including visceral, neurological and psychiatric manifestations, the disease can be overlooked or its diagnosis can be delayed $(2,3,5)$. Neurological manifestations include vertical supranuclear gaze palsy, ataxia, dysarthria, dysphagia, clumsiness, dystonia, hypotonia, gelastic cataplexy, pyramidal signs, and spasticity $(1,2,6)$. Filipin staining and genetic tests are important to confirm the diagnosis of NP-C $(3,5,6)$. Previous studies have focused on multidisciplinary approach including disease-specific treatment and symptomatic treatment $(3,5,6)$. However, the role of rehabilitation in cases with NP-C has not been highlighted thoroughly. Accordingly; in this case, we would like to highlight the role of rehabilitation in the management of a patient with NP-C.

\section{CASE REPORT}

An 8-year-old female patient presented to our clinic with weakness of the lower limb muscles and walking difficulty. She had a history of falls since she was three years old; while prenatal, natal and postnatal development was normal. She stated that she had been diagnosed with Niemann Pick Disease 
Type-C according to her skin biopsy and filipin test results. She had been under miglustat treatment for five years. She could not ambulate independently for the last year.

On physical examination, she was not able to ambulate independently. Varus deformity of the right knee and right ankle and genu recurvatum of bilateral knees were present during verticalisation with a person's assistance (Figure 1). Body balance was insufficient. Functional Ambulation Classification (FAC) score was 1. She had a restriction in right ankle joint and grade 2 spasticity according to the Modified Ashworth Scale in gastrocnemius and tibialis posterior muscles. Also, grade 1 spasticity was present in left gastrocnemius and tibialis posterior muscles. Bilateral ankle dorsiflexor and plantar flexor muscles' strength were 1/5; in addition, right limb extremity muscles strength was 2/5 and left lower limb muscles' strength was 3/5. Deep tendon reflexes were hyperactive with positive Hoffman, Babinski and clonus signs. Moreover, she had dysarthria.

Laboratory tests were normal. Brain magnetic resonance imaging (MRI) showed cerebellar atrophy. Fiberoptic endoscopic evaluation of swallowing and hearing tests were normal. Electromyography (EMG) was normal. Abdominal ultrasound showed enlargement of both the liver and spleen.

Bilateral static plastic knee-ankle-foot orthosis (KAFO) was recommended for preventing joint contractures. The patient received a comprehensive rehabilitation program including the range of motion exercises, posture, gait, balance training and neurophysiological exercises for five days per week for eight weeks. Stretching exercises of gastrocnemius and tibialis posterior muscles and heat pack (before stretching) were applied. As for the weakness of lower extremity and lack of knee locking, strengthening exercises of knee extensor and ankle dorsiflexor muscles were performed with submaximal intensity. Besides, electrical stimulation was applied to the ankle dorsiflexors. She also received speech and occupational therapy. Her body balance improved and she was able to verticalize in parallel bars with bilateral KAFOs after a-four week inpatient rehabilitation program. She underwent 10 sessions of lower limb robot-assisted training. After verticalization and weight bearing training, she received ambulation, balance and coordination training with KAFOs in parallel bars. Thereafter she received gait training with KAFOs and reverse walker. Her knee extensor muscles' strength increased and she started to walk with ankle-foot-orthosis (AFO) in parallel bars (Figure 2). Nevertheless, ambulation with AFOs and reverse walker was not recommended in this stage because of failure of knee locking and fall risk. After the rehabilitation program, her ankle restriction significantly improved and she could ambulate with KAFOs, reverse walker and a person's intermittent light touch assistance (Figure 3). FAC score improved to 2. After 30 sessions of speech and occupational therapy, her speech and hand functions improved. She was able to eat solid and semisolid foods with the spoon without any assistance. Written informed consent was obtained from the patient's family.

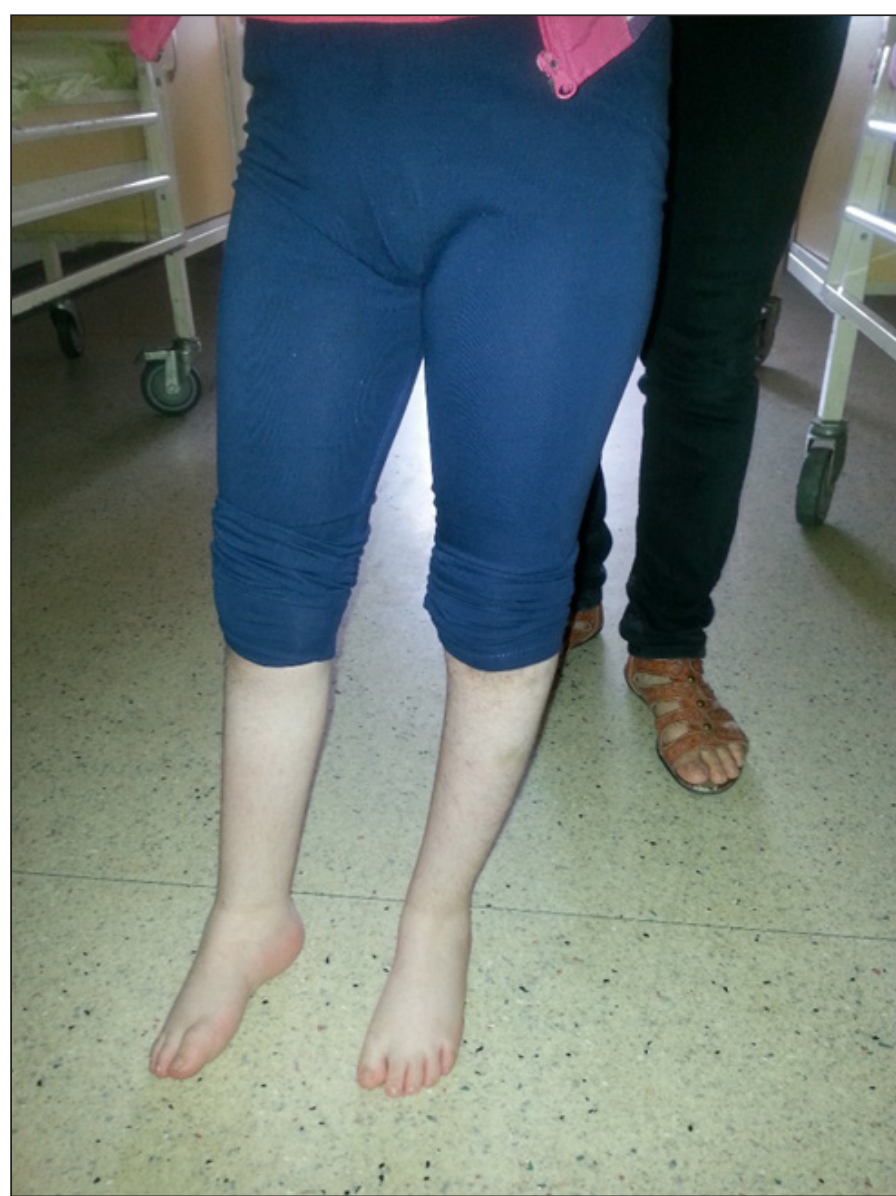

Figure 1: An 8-year-old female patient, She had varus deformity of right knee and right ankle with genu recurvatum of bilateral knees during verticalisation with a person assistance.

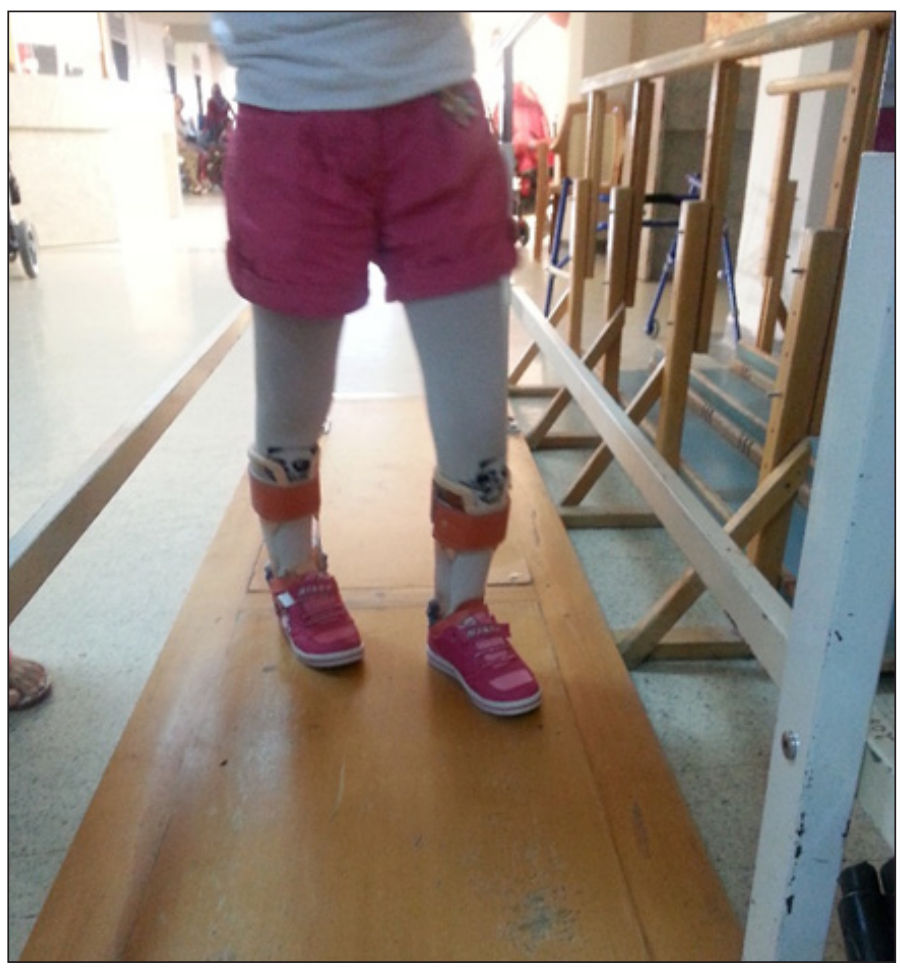

Figure 2: She could walk with ankle-foot-orthosis (AFO) in parallel bars. 


\section{DISCUSSION}

Clinical presentation of NP-C is very heterogeneous. The onset age of the illness has a variable range between the prenatal period and adulthood (4). In addition, NP-C can present with a wide variety of clinical patterns including visceral, neurological and psychiatric manifestations which can be seen alone or in combination (3). Due to the heterogeneity of the disease, diagnosis of the illness is prolonged for five-six years from the onset of the neurological signs $(2,3)$. Our patient was diagnosed with NP-C within a few months after the initial neurological symptoms. Also, miglustat treatment was started in the early stage of the disease. Clinical presentation is categorized as early infantile period ( 2 months- 2 years), late infantile period (2 to 6 years), juvenile period (6-15 years), adolescent, and adults period (>15 years) (4). Neurological signs include vertical supranuclear gaze palsy, gelastic cataplexy, ataxia, dystonia, dysarthria, dysphagia, hypotonia, clumsiness, delayed developmental milestones, seizures, and hearing loss (3). Pyramidal signs and spasticity can develop $(1,6)$. Our patient presented to the pediatrics clinic with the complaints of gait problems and falls at three years old.

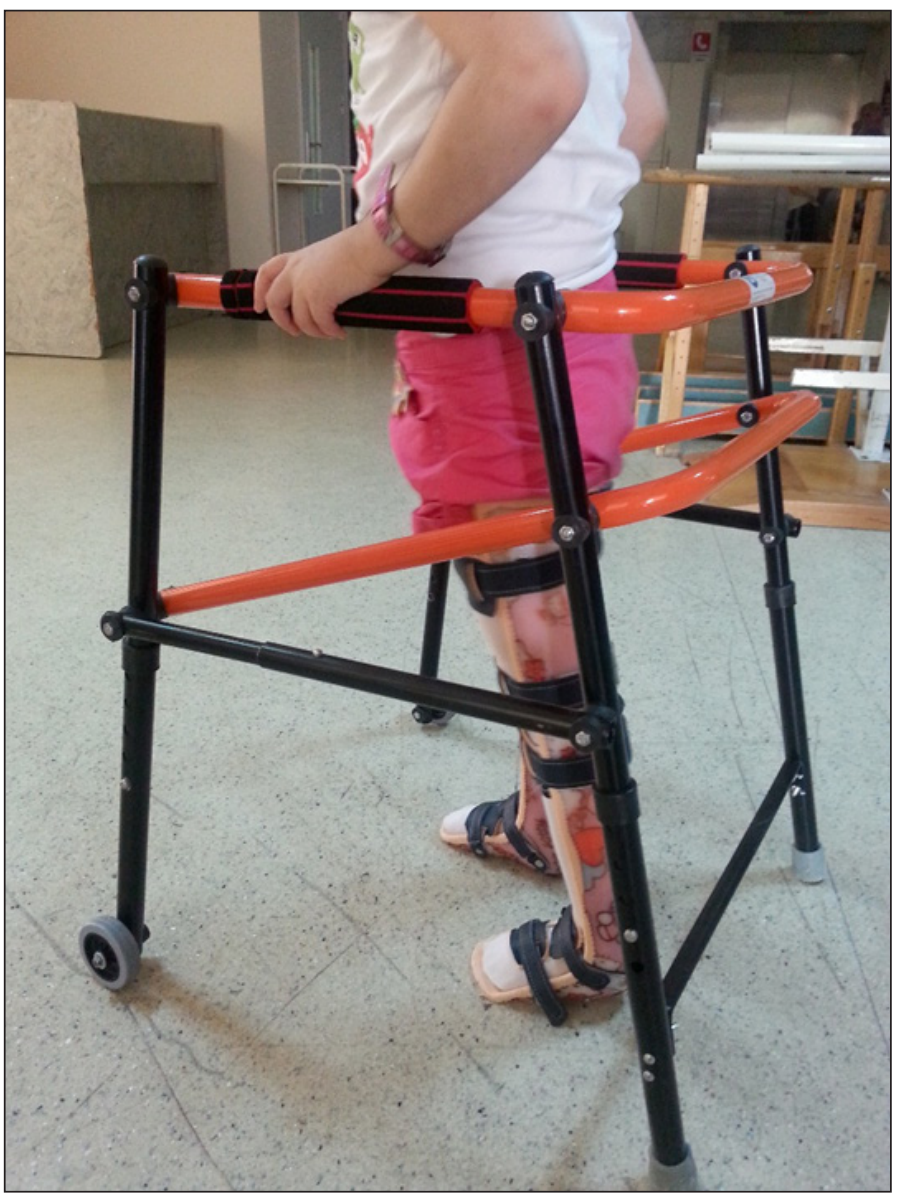

Figure 3: She could ambulate with KAFOs, reverse walker and a person's intermittent light touch assistance.
After a careful medical history, a comprehensive physical and neurological examination should be performed $(2,4)$. Ophthalmological assessment, swallowing tests, hearing tests, and psychometric assessment are also required (4). Our patient had spasticity in bilateral gastrocnemius and tibialis posterior muscles, besides lower limb muscle weakness. Her reflexes were hyperactive with positive Hoffman, Babinski and clonus signs. Her walking got worse progressively in four years and she did not ambulate independently for the last one year. Her hearing test and fiberoptic endoscopic evaluation of swallowing were normal. Filipin staining test and genetic test are important in confirming the diagnosis of NP-C $(3,5,6)$. Skin biopsy was performed in our patient and the NP-C diagnosis was confirmed with the filipin test. Although MRI or spectroscopy do not show any specific pathological imaging for NP-C, they can show the presence or progression of neurological disease (2). Additionally, cerebellar atrophy may be shown (2). The MRI of our patient showed cerebellar atrophy as well.

Neurological manifestations affect both the patient's and the families' lives (4). Early diagnosis and appropriate approach including symptomatic and disease-specific treatment can enhance the patient's quality of life (5). Our patient was under miglustat treatment, which was approved for treatment of progressive neurological manifestations, for five years (7).

To the best of our knowledge, medical treatment of NP-C is emphasized in previous studies. In this case, we herein emphasize the rehabilitation part of NP-C treatment, due to the progression of the disease. Patients with NP-C may unable to walk and sit in the later stage of the disease. A rehabilitation program could slow down the development of complications and secondary disabilities. Our patient received an individualspecific rehabilitation program considering the physical examination and the patient's neurological deficits. She received gait, balance, coordination training, range of motion exercises, 10 sessions of lower limb robot-assisted training, 30 sessions of speech and occupational therapy. Although EMG did not show myopathy, excessively strenuous exercise was avoided and submaximal strengthening exercise was applied. Stretching and heat application before stretching was performed for spasticity. While she could not ambulate independently for the last one year; her muscle strength increased and her body balance and ankle joint restriction improved. She was able to ambulate with KAFOs and reverse walker with a person's intermittent light touch assistance after the eight-week rehabilitation program. Due to swallowing, hearing and speech disorders in patients with NP-C, swallowing and speech therapy must be a part of the rehabilitation program. After 30 sessions of speech and occupational therapy, our patient's speech and hand skills improved. Patterson et al. (5) recommended video recordings of clinical examinations to evaluate neurological progression and changes in ambulation. Using simple 10-meter walk tests was also suggested (5). 
In conclusion, we highlight that rehabilitation program must be a part of the treatment in patients with NP-C for improving the quality of life and protecting patients from complications of illness and immobilization. Studies are required for a safe rehabilitation program in patients with NP-C.

\section{REFERENCES}

1. Abela L, Plecko B, Palla A, Burda P, Nuoffer J-M, Ballhausen D, et al. Early co-occurrence of a neurologic-psychiatric disease pattern in Niemann-Pick type C disease: A retrospective Swiss cohort study. Orphanet J Rare Dis 2014;9:176.

2. Burlina A. Niemann-Pick disease type C: Introduction and main clinical features. J Neurol 2014; 261 Suppl:S525-7.
3. Mengel E, Klünemann HH, Lourenço CM, Hendriksz CJ, Sedel F, Walterfang M, et al. Niemann-Pick disease type C symptomatology: An expert-based clinical description. Orphanet $J$ Rare Dis 2013;8:166.

4. Vanier MT. Niemann-Pick disease type C. Orphanet J Rare Dis 2010;5:16.

5. Patterson MC, Hendriksz CJ, Walterfang M, Sedel F, Vanier MT, Wijburg F, et al. Recommendations for the diagnosis and management of Niemann-Pick disease type C: An update. Mol Genet Metab 2012;106:330-44.

6. Vanier MT. Niemann-Pick diseases. Handb Clin Neurol 2013;113:1717-21.

7. Patterson MC, Vecchio D, Jacklin E, Abel L, Chadha-Boreham $\mathrm{H}$, Luzy $\mathrm{C}$, et al. Long-term miglustat therapy in children with Niemann-Pick disease type C. J Child Neurol 2010;25:300-5. 